\title{
Conservation of S20 as an Ineffective and Disposable IFN $\gamma$-Inducing Determinant of Plasmodium Sporozoites Indicates Diversion of Cellular Immunity
}

\section{OPEN ACCESS}

Edited by:

Yongliang Zhang,

National University of Singapore,

Singapore

Reviewed by:

Sanjeev Kumar,

Assam University, India

Jessica N. McCaffery,

Centers for Disease Control and Prevention (CDC), United States

Rajesh Chandramohanadas,

National University of Singapore,

Singapore

*Correspondence:

Kai Matuschewsk

Kai.Matuschewski@hu-berlin.de

${ }^{\dagger}$ Present address:

Diana Scheppan,

The Lübeck Institute of Experimental

Dermatology, University Medical Center Schleswig-Holstein, Lübeck,

Germany

Specialty section:

This article was submitted to

Infectious Diseases,

a section of the journal

Frontiers in Microbiology

Received: 30 April 2021

Accepted: 07 July 2021

Published: 06 August 2021

Citation:

Hon C, Friesen J, Ingmundson A, Scheppan D, Hafalla JCR, Müller K and Matuschewski K (2021) Conservation of $\mathrm{S} 2 \mathrm{O}$ as an Ineffective and Disposable IFN $\gamma$-Inducing

Determinant of Plasmodium Sporozoites Indicates Diversion

of Cellular Immunity.

Front. Microbiol. 12:703804 doi: 10.3389/fmicb.2021.703804

\section{Calvin Hon ${ }^{1}$, Johannes Friesen²,3, Alyssa Ingmundson 1,2, Diana Scheppan'2t, Julius C. R. Hafalla ${ }^{4}$, Katja Müller ${ }^{1,2}$ and Kai Matuschewski1,2*}

\footnotetext{
${ }^{1}$ Department of Molecular Parasitology, Institute of Biology, Humboldt University, Berlin, Germany, ${ }^{2}$ Parasitology Unit, Max Planck Institute for Infection Biology, Berlin, Germany, ${ }^{3}$ Medical Care Unit Labor 28 GmbH, Berlin, Germany, ${ }^{4}$ Department of Infection Biology, London School of Hygiene \& Tropical Medicine, London, United Kingdom
}

Despite many decades of research to develop a malaria vaccine, only one vaccine candidate has been explored in pivotal phase III clinical trials. This candidate subunit vaccine consists of a portion of a single Plasmodium antigen, circumsporozoite protein (CSP). This antigen was initially identified in the murine malaria model and shown to contain an immunodominant and protective $\mathrm{CD}^{+}{ }^{+} \mathrm{T}$ cell epitope specific to the $\mathrm{H}-2 \mathrm{~K}^{d}$ (BALB/c)-restricted genetic background. A high-content screen for $\mathrm{CD}^{+}$epitopes in the $\mathrm{H} 2 \mathrm{~K}^{b} / \mathrm{D}^{b}$ (C57BL/6)-restricted genetic background, identified two distinct dominant epitopes. In this study, we present a characterization of one corresponding antigen, the Plasmodium sporozoite-specific protein S20. Plasmodium berghei S20 knockout sporozoites and liver stages developed normally in vitro and in vivo. This potent infectivity of $s 20(-)$ sporozoites permitted comparative analysis of knockout and wild-type parasites in cell-based vaccination. Protective immunity of irradiation-arrested s2O(-) sporozoites in single, double and triple immunizations was similar to irradiated unaltered sporozoites in homologous challenge experiments. These findings demonstrate the presence of an immunogenic Plasmodium pre-erythrocytic determinant, which is not essential for eliciting protection. Although S2O is not needed for colonization of the mammalian host and for initiation of a blood infection, it is conserved amongst Plasmodium species. Malarial parasites express conserved, immunogenic proteins that are not required to establish infection but might play potential roles in diverting cellular immune responses.

Keywords: malaria, Plasmodium, sporozoite, whole organism vaccine, antigen, CD8 ${ }^{+} \mathrm{T}$ cells, immunization, preerythrocytic stage

\section{INTRODUCTION}

Sustained anti-malaria therapy, exposure prophylaxis, and vector control have resulted in stable incidence and mortality rates in the tropics (World Health Organisation, 2020). To reduce global malaria burden and transmission of Plasmodium parasites, access to a safe and efficacious prophylactic vaccine will be needed. An established method to achieve lasting sterile protection 
against natural Plasmodium sporozoite infection is intravenous administration of multiple doses of live $\gamma$-irradiation-attenuated sporozoites ( $\gamma \mathrm{spz}$ ) (Nussenzweig et al., 1967; Clyde et al., 1973; Hoffman et al., 2002; Richie et al., 2015). Identification of immunogenic antigens and immune correlates of protection vs. sporozoite exposure remain research priorities to develop second-generation sporozoite vaccines.

Protective sporozoite-induced immunity is achieved by complementary humoral and cellular memory responses (Rodrigues et al., 1993; Hafalla et al., 2011). Previous studies using $\gamma \mathrm{spz}$ vaccination in mice have revealed the pivotal role of circulating and liver-resident $\mathrm{CD}^{+} \mathrm{T}$ cells in mediating protective immunity to the pre-erythrocytic stages of the parasite by cytolytic killing (Ferreira et al., 1986; Schofield et al., 1987; Weiss et al., 1988; Guebre-Xabier et al., 1999; Krzych et al., 2000; Schmidt et al., 2008). Antigen-specific, cytolytic $\mathrm{CD}^{+} \mathrm{T}$ cells target infected hepatocytes, which present MHC I-restricted parasite peptides on the cell surface (Romero et al., 1989; Rodrigues et al., 1991). Upon peptide recognition by $\mathrm{CD}^{+} \mathrm{T}$ cells, cytokines such as interferon- $\gamma$ (IFN $\gamma$ ) (Schofield et al., 1987) and tumor necrosis factor (TNF) (Butler et al., 2010; Depinay et al., 2011) are released along with pro-apoptotic pore-forming lytic proteins, perforin and granzymes. The central role of $\mathrm{CD}^{+} \mathrm{T}$ cells in pre-erythrocytic stage immunity has been further highlighted by several studies, where abrogation of immunity in $\gamma \mathrm{spz}$-immunized mice and non-human primates was observed after in vivo depletion of $\mathrm{CD}^{+} \mathrm{T}$ cells (Schofield et al., 1987; Weiss et al., 1988; Doolan and Hoffman, 2000; Weiss and Jiang, 2012). $\mathrm{CD}^{+} \mathrm{T}$ cells, however, are less likely to confer protection during the asexual parasite growth inside erythrocytes, simply because MHC I molecules are not found on the surface of mammalian erythrocytes. Accordingly, the key role of cytolytic $\mathrm{CD}^{+} \mathrm{T}$ cells in sustained protection is largely restricted to the first obligate parasite expansion phase in the liver.

Despite decades of considerable investments in malaria research, only one malaria vaccine has been licensed to-date, known as the RTS,S/AS01 (RTS,S Clinical Trials Partnership, 2015; Neafsey et al., 2015). This subunit vaccine is based on the major Plasmodium falciparum sporozoite surface antigen, termed circumsporozoite protein (CSP) (Cohen et al., 2010). CSP is highly conserved amongst Plasmodium species, and essential for sporozoite formation, motility and hepatocyte adhesion. It contains a central repeat structure, which likely further contributes to immune-dominance over minor sporozoite surface antigens (Zavala et al., 1983; Zavala et al., 1985). Modest protection offered by this vaccine is strongly associated with humoral immunity and, to a lesser extent, T-cell mediated responses (Stoute et al., 1998; Cohen et al., 2010). Employing murine malaria models it was shown that CSP contains immunogenic targets of protective $\mathrm{H} 2-\mathrm{K}^{d}$-restricted $\mathrm{CD}{ }^{+} \mathrm{T}$ cell responses that are vital for protection against sporozoite infections (Rodrigues et al., 1991; Sedegah et al., 1992). But more recent studies have shown that sterile protection can also be achieved in the absence of CSP-specific T cells (Kumar et al., 2006; Grüner et al., 2007; Gibbins et al., 2020). While these findings might partly explain the inadequate protective efficacy of the
RTS,S/AS01 vaccine they also highlight the need to investigate non-CSP antigens.

For the identification and evaluation of immunogenic preerythrocytic stage $\mathrm{CD} 8^{+} \mathrm{T}$ cell epitopes two inbred mice strains, $\mathrm{H} 2-\mathrm{K} / \mathrm{D}^{b}$ - and $\mathrm{H} 2-\mathrm{K}^{d}$-restricted $\mathrm{C} 57 \mathrm{BL} / 6$ (B6) and $\mathrm{BALB} / \mathrm{c}$ mice, respectively, have been largely used. Immunizing either mouse strains with Plasmodium berghei $(\mathrm{Pb})$ or Plasmodium yoelii $(P y) \gamma \mathrm{spz}$ is able to induce highly protective responses (Romero et al., 1989; Rodrigues et al., 1991; Sano et al., 2001). Candidate $\mathrm{CD}^{+} \mathrm{T}$ cell epitopes are typically selected based on the amount of IFN $\gamma$ from activated $\mathrm{CD}^{+} \mathrm{T}$ cells upon stimulation with soluble peptides as a proxy for recognition of immunogenic MHC I-restricted epitopes. Between the two mouse strains, B6 mice appear to represent a more accurate model for immunological studies as the elicited $\mathrm{H} 2-\mathrm{K}^{b}$-restricted $\mathrm{CD}^{+} \mathrm{T}$ cell responses during sporozoite infection are more diverse. Reliance on multiple doses for protective immunity suggest a closer resemblance to that of humans, in contrast to the ease of eliciting protective immunity in $\mathrm{BALB} / \mathrm{c}$ mice due to the immunodominance of the CSP epitope (Hafalla et al., 2013). Furthermore, the inability of B6 mice to recognize the $\mathrm{H} 2$ $\mathrm{K}^{d}$-restricted CSP epitope as a consequence of MHC haplotype restriction allows identification of non-CSP-mediated immunity. A genome-wide screening for candidate pre-erythrocytic stage $\mathrm{H} 2-\mathrm{K} / \mathrm{D}^{b}$-restricted $\mathrm{CD} 8^{+} \mathrm{T}$ cell epitopes in $\mathrm{B} 6$ mice returned only two epitopes that correlate with protracted $\mathrm{CD}^{+} \mathrm{T}$ cell responses (Hafalla et al., 2013). One $\mathrm{H}_{2}-\mathrm{D}^{b}$-restricted epitope originated from the thrombospondin-related adhesion protein $\left(\mathrm{TRAP}_{130-138}\right)$ and displayed cytotoxic $\mathrm{CD}^{+} \mathrm{T}$ cell responses after a single immunization with $\gamma$ spz. Importantly, partial protection could be achieved by eliciting high levels of TRAPspecific $\mathrm{CD}^{+} \mathrm{T}$ cells via a heterologous prime-boost regimen.

Strikingly, the other identified $\mathrm{H} 2-\mathrm{K}^{b}$-restricted target of $\mathrm{CD}^{+} \mathrm{T}$ cells $\left(\mathrm{S}^{+} \mathrm{O}_{318-326}\right)$ found in that screening, which maps to the sporozoite-specific gene 20 (Kaiser et al., 2004), did not induce cytotoxic immune responses. In good agreement, tolerization with $\mathrm{S}_{20} \mathrm{O}_{318-326}$ peptide failed to completely reverse protection, in contrast to $\mathrm{TRAP}_{130-138}$ (Hafalla et al., 2013). In this study, we aimed to investigate this unusual $\mathrm{CD}^{+} \mathrm{T}$ cell response by generating $S 20$ knock-out parasites to confirm the origin of the epitope and to study potential contributions of $\mathrm{S}_{2} \mathrm{O}_{318-326}$ toward protection in whole sporozoite immunizations.

\section{RESULTS}

\section{S20 Is Highly Conserved Among Plasmodium Species and Primarily Expressed in Sporozoites}

Since the sporozoite-specific protein S20 (PBANKA_1429200) was first identified in Vinckeia species (Kaiser et al., 2004), we first verified whether it is also present in other Plasmodium species and Toxoplasma gondii. This analysis revealed S20 orthologs in all Plasmodium species and a similar protein in T. gondii (TGGT1_229000). Examples of representative apicomplexan S20 


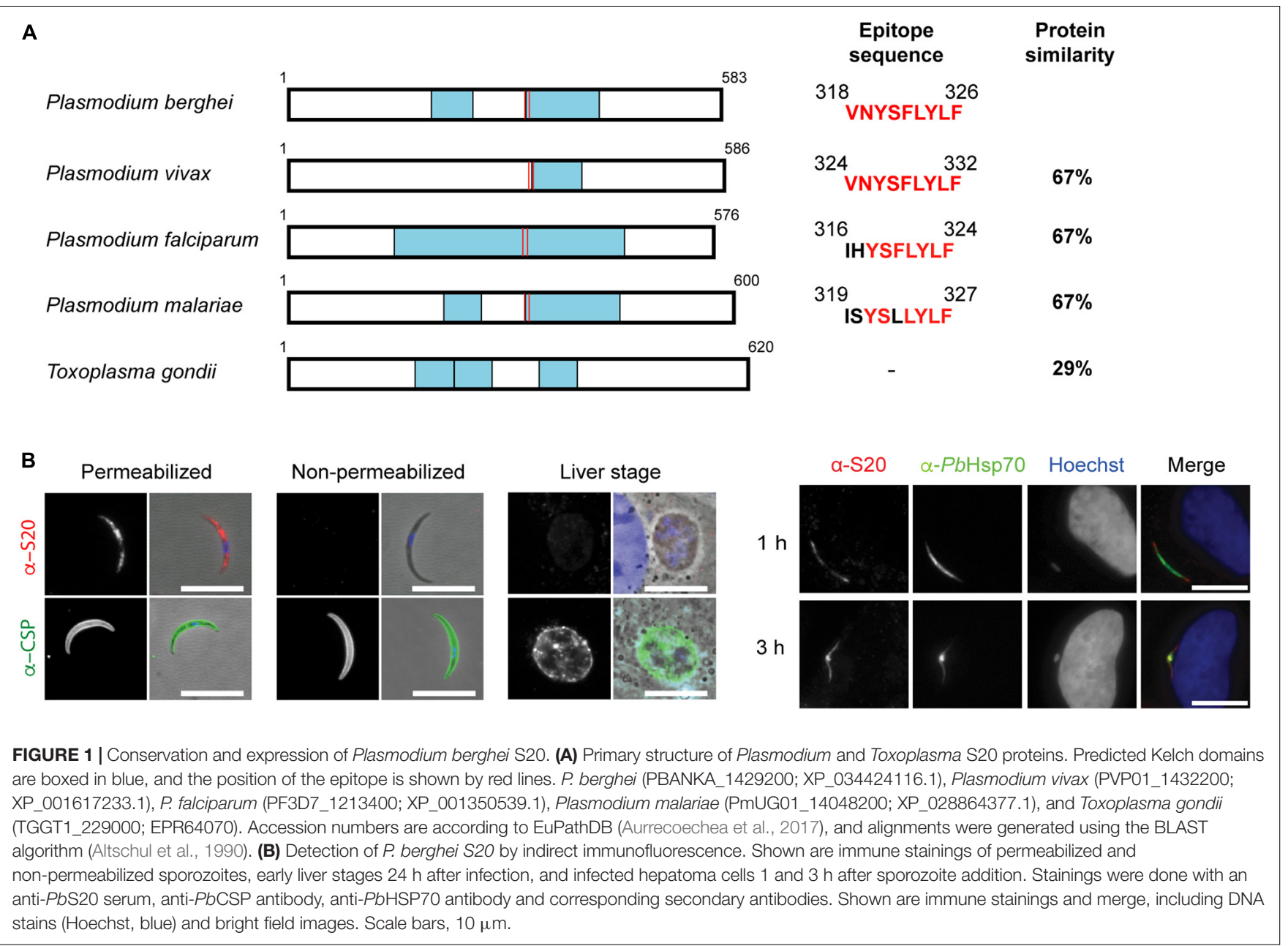

orthologs are displayed in Figure 1A. S20 orthologs are also present in other Coccidia, for instance Sarcocystis neurona (SRCN_6348), Besnoitia besnoiti (BESB_083580), Eimeria tenella (ETH_00029095), and Cyclospora cayetanensis (cyc_00626), but not Piroplasms. S20 proteins contain kelch motifs, segments of approximately 50 amino acid residues that form a single four-stranded, antiparallel beta-sheet (Bork and Doolittle, 1994). Kelch motifs are widely distributed in eukaryotic and prokaryotic proteins with divergent functions. The high degree of S20 protein sequence conservation among Plasmodium is indicative of a possible conserved function. The sequence of $\mathrm{H} 2-\mathrm{K}^{b}$-restricted epitope VNYSFLYFL (Hafalla et al., 2013) is also relatively well maintained across Plasmodium species.

We next profiled S20 expression in pre-erythrocytic stages. In good agreement with published data (Kaiser et al., 2004), we detected up-regulation of PbS20 mRNA in midgut and salivary gland sporozoites (Supplementary Figure 1). As expected, the relative transcript abundance of $S 20$ was lower than the steady state levels of the CSP transcripts that encode the major sporozoite surface protein. Transcript levels dropped toward the end of liver stage maturation and remained low during blood infection (Supplementary Figure 1), in good agreement with the original description (Kaiser et al., 2004).
In order to gain insights into protein expression and localization, we generated polyclonal anti- $P b S 20$ peptide sera. S20 could be detected in salivary gland sporozoites and in sporozoites that recently invaded hepatoma cells (Figure 1B). However, $24 \mathrm{~h}$ after invasion, S20 was no longer detectable. The S20 antisera could only recognize S20 in sporozoites that had been permeabilized, which indicates that in contrast to CSP, S20 is restricted to the sporozoite interior. The specificity of the $S 20$ signal in sporozoites was verified in immunofluorescence assays (IFAs) using s20(-) P. berghei, where no signal was detected (Figure 2D; see below).

\section{Targeted Deletion of Plasmodium berghei S2O}

We were interested in characterizing potential roles of PbS20 for sporozoite transmission and liver infection and to explore the contribution of $\mathrm{S}_{2} \mathrm{O}_{318}-326^{-}$-specific $\mathrm{CD} 8^{+} \mathrm{T}$ cell responses to immunity elicited by whole sporozoite immunization. However, the latter can only be tested using this strategy if $s 20(-)$ sporozoites induce blood infections as efficiently as wild-type (WT) sporozoites. To this end, we deleted PbS20 by double homologous recombination to replace the open reading frame 


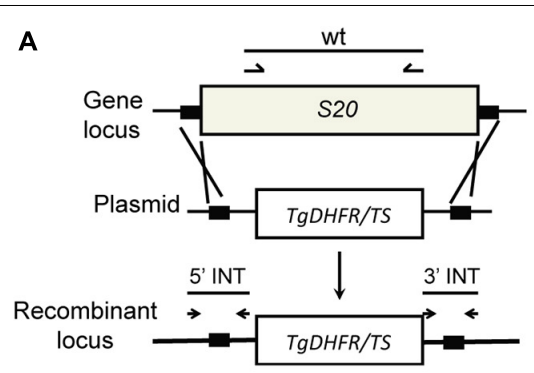

C

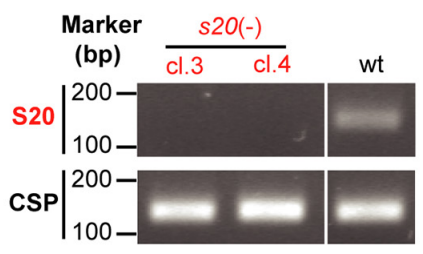

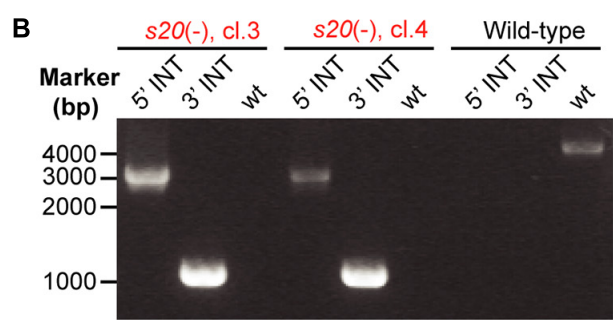

D

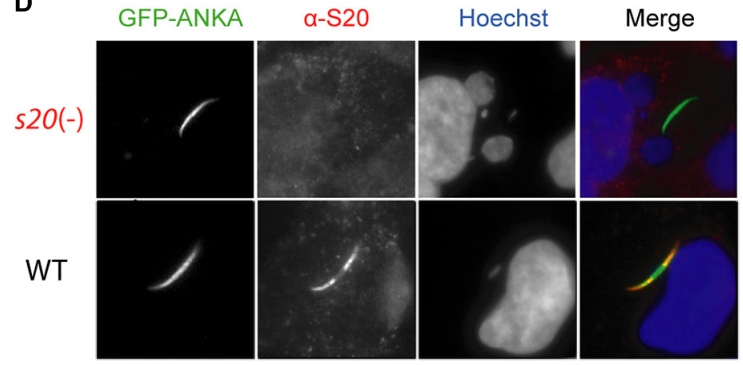

FIGURE 2 | Targeted gene deletion of $P$. berghei S20. (A) Schematic diagram of the replacement strategy to generate s2O(-) parasites. After linearization with Sacll and Kpnl, the replacement vector containing portions of the $5^{\prime}$ and $3^{\prime}$ flanking regions of $S 20$ coding sequence and the Toxoplasma gondii dihydrofolate reductase/thymidylate synthase (Tgdhfr/ts) selectable marker was transfected into P. berghei ANKA wild-type parasites. (B) Diagnostic PCR to confirm successful replacement of the $S 20$ genomic locus with the positive selection marker in $520(-)$ parasites. Shown are the results from clone 3 and $4.5^{\prime}$ - and $3^{\prime}$-integration-specific primer combinations ( $5^{\prime}$ INT and $3^{\prime}$ INT) amplify the predicted fragment only in the recombinant locus. Wild-type-specific primer pairs (wt) do not produce a PCR fragment in the recombinant locus confirming absence of residual WT parasites. (C) Verification of absence of $S 20$ transcripts in $s 20(-)$ clones 3 and 4 salivary gland sporozoites by RT-PCR. Note that s20 mRNA (top) is only detectable in WT sporozoites. CSP mRNA (bottom) serves as positive control. (D) Indirect immunofluorescent stainings of permeabilized infected hepatoma cells $1 \mathrm{~h}$ after s2O(-) (top) or WT (bottom) sporozoite addition. Stainings were done with anti-GFP antibody, an anti-PbS20 serum, and corresponding secondary antibodies. Shown are immune stainings, DNA stains (Hoechst, blue) and merge images.

with the $T g d h f r / t s$ resistance cassette for positive selection in vivo (Figure 2A). Successful transfection and cloning by limiting dilution resulted in clonal $s 20(-)$ parasites. For this study, two clonal parasite populations, termed clones 3 and 4, were obtained after two independent transfection experiments. Genotyping by diagnostic PCR verified the desired gene deletion and absence of WT parasites from the clonal lines (Figure 2B). Additional confirmation of the absence of $S 20$ was obtained by RT-PCR from total RNA isolated from $s 20(-)$ and WT salivary gland sporozoites (Figure 2C). In contrast to CSP control transcripts, S20 mRNA was only present in WT, but not in $s 20(-)$ sporozoites. As noted above, immunofluorescent staining using the polyclonal anti-PbS20 peptide sera for WT- and s20(-)-infected hepatoma cells showed a loss of signal in $s 20(-)$, but not WT, parasites (Figure 2D). Because initial analysis revealed that both clonal parasite populations are phenotypically indistinguishable, one population (clone 4) was selected for the experiments to uncover the roles of $S 20$ in Plasmodium life cycle progression and subsequently, the $\mathrm{H} 2-\mathrm{K}^{b}$-restricted $\mathrm{S} 20318-326 \mathrm{CD}^{+} \mathrm{T}$ cell epitope in vaccine-induced protection. Swift selection of asexual $s 20(-)$ parasites corroborated the notion that $S 20$ is not required for Plasmodium blood infection.

\section{s20(-) Sporozoites Display Full Infectivity to Mice}

Conservation of S20 across all Plasmodium species might indicate critical functions during pre-erythrocytic stages. Accordingly, we monitored life cycle progression in the mosquito vector and during sporozoite transmission. Quantification of $s 20(-)$ midgut oocysts and salivary gland sporozoites from infected Anopheles mosquitoes showed no differences in comparison to WT parasites (Supplementary Table 1).

Salivary gland sporozoites were isolated and analyzed for their capacity to perform gliding locomotion and infect cultured hepatoma cells and mice (Figure 3). Freshly isolated s20(-) sporozoites displayed continuous, circular gliding locomotion on BSA-coated glass slides similar to WT parasites (Figure 3A). When deposited onto cultured Huh7 hepatoma cells, formation of liver stages was indistinguishable from WT parasites, both quantitatively and morphologically (Figures 3B,C). To rule out any defects in sporozoite infectivity in vivo, prepatency, i.e., the time to detection of the first blood stage parasite, and the course of blood infection were determined by daily microscopic examination of blood films from B6 mice following intravenous injection of 10,000 s20(-) or WT salivary gland sporozoites, or exposure of the mice to bites of $s 20(-)$ or WT-infected mosquitoes (Figure $3 \mathrm{D}$ and Supplementary Table 2). All mice infected with either s20(-) or WT intravenously or by mosquito bites were blood stagepositive on day 3 after sporozoite inoculation. No differences in the course of blood infection between the two parasite groups were detectable. In good agreement, quantification of the relative liver infection load $42 \mathrm{~h}$ after intravenous delivery of 10,000 sporozoites by quantitative RT-PCR (qRT-PCR) 
A
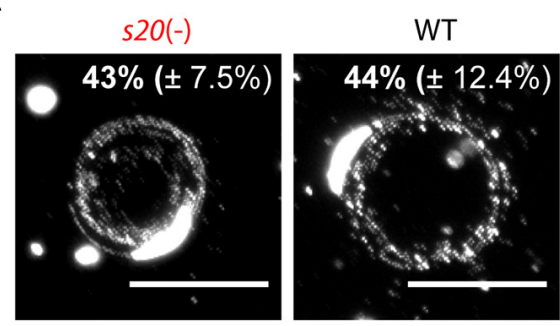

C

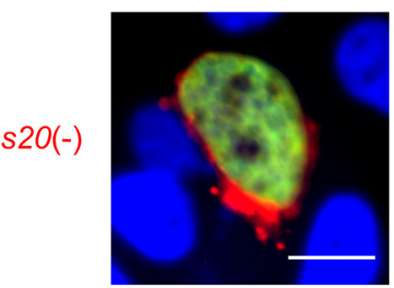

Merge
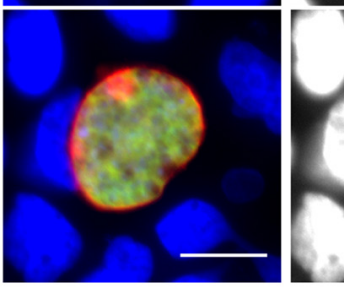

D

Intravenous infection

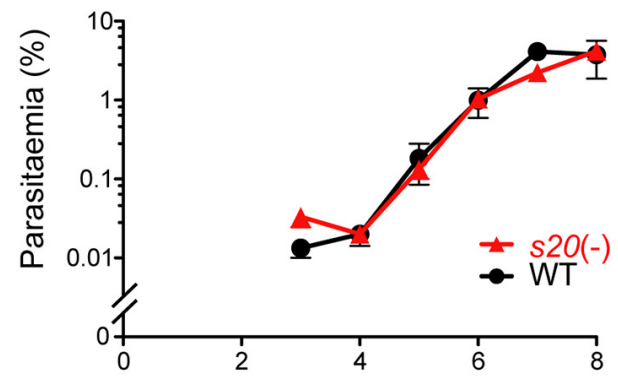

B

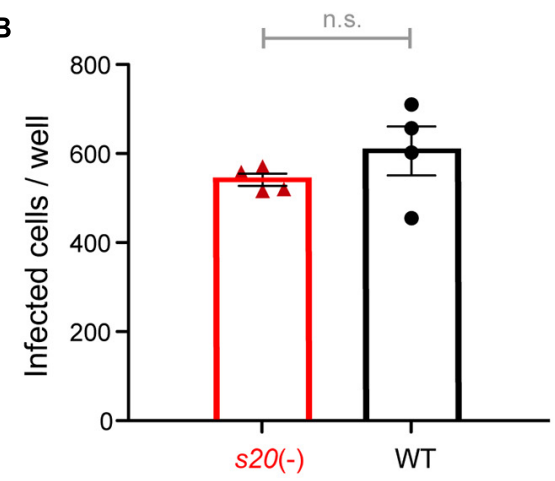

a-HSP70
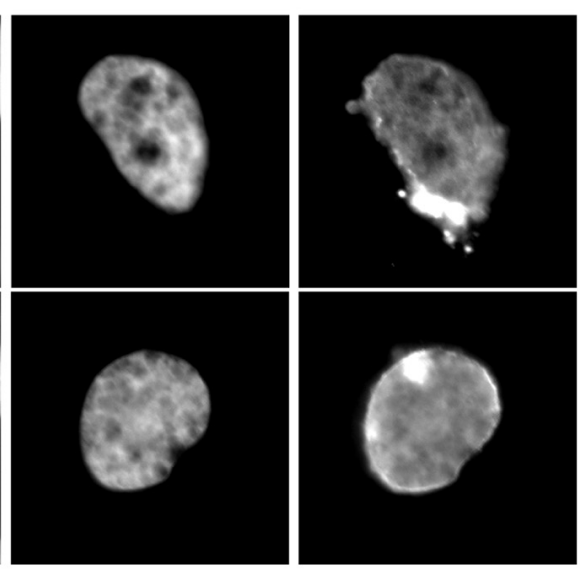

Mosquito infection

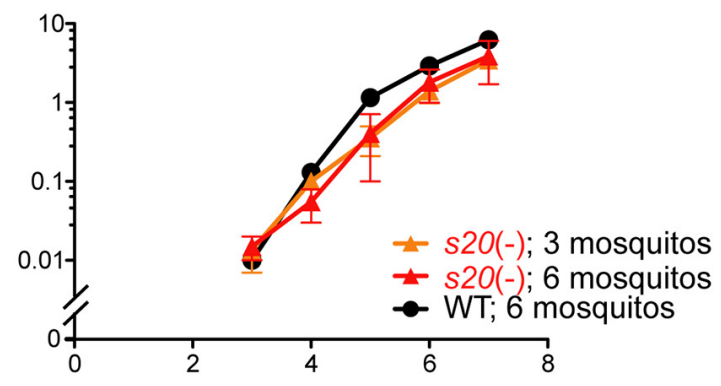

Time after sporozoite infection (d)

FIGURE 3 | Normal life cycle progression of s20(-) parasites. (A) Fluorescence micrographs of s20(-) and WT sporozoites that were permitted to glide on BSA-coated glass slides. Sporozoites and trails are visualized with an anti-PbCSP and anti-mouse secondary antibodies. Numbers show mean percentage ( \pm SD) of gliding sporozoites. (B) Quantification of s2O(-) and WT-infected hepatoma (Huh7) cells by fluorescence microscopy $48 \mathrm{~h}$ after infection. Shown are mean values ( \pm SEM); $n=1$; n.s., non-significant (unpaired $t$-test). (C) Representative fluorescence images of s2O(-) and WT liver stages. $\alpha$-HSP70 antibody (green; parasite cytoplasm), $\alpha$-UIS4 antibody (red; parasitophorous vacuole), and Hoechst (blue; nucleic acid). Scale bars, $10 \mu \mathrm{m}$. (D) Blood infection after sporozoite-induced infection. B6 mice were infected by intravenous injection of 10,000 s20(-) or WT sporozoites ( $n=3$ each) or mosquito bites (WT, six infected mosquitoes, $n=1$; s20(-), 3 or 6 infected mosquitoes, $n=2$ each). Blood infection was monitored by daily microscopic examination of Giemsa-stained blood films. Shown are mean values ( \pm SEM).

revealed no difference between s20(-) and WT parasites (Supplementary Figure 2).

Together, s20(-) sporozoites displayed no apparent defects in sporozoite, liver stage or blood stage functions, permitting its use in immunization protocols.

\section{Effective Immunizations With Irradiated s20(-) Sporozoites}

Intravenous immunizations with metabolically active, irradiation-attenuated sporozoites remains the benchmark for pre-clinical and clinical evaluation of experimental malaria 
TABLE 1 | Vaccine-induced protection against WT sporozoite challenge infections.

\begin{tabular}{lcc}
\hline Immunizations $^{\mathbf{1}}$ & Protected/challenged & Prepatency $^{2}$ \\
\hline $3 \times 10,000 \mathrm{WT} \gamma \mathrm{spz}$ & $10 / 10(100 \%)$ & - \\
$3 \times 10,000 \mathrm{~s} 20(-) \gamma \mathrm{spz}$ & $9 / 9(100 \%)$ & - \\
none & $0 / 3(0 \%)$ & day 3
\end{tabular}

${ }^{1}$ Immunizations were done by intravenous injection of irradiated $(\gamma)$ sporozoites.

${ }^{2}$ Prepatency is defined as time to the first detection of a single blood stage parasite.

vaccines. In humans and mice, sterile protection against sporozoite-induced infections can be routinely achieved after multiple doses of $\gamma \mathrm{spz}$ (Nussenzweig et al., 1967; Hoffman et al., 2002, 2010). We initiated our study by immunizing groups of mice with three doses of $10,000 \gamma \mathrm{spz}$. Immunized and control animals were infected by a challenge dose of 10,000 WT sporozoites 29 days after the last immunization (Table 1). All immunized animals remained blood stage negative, while the control animals became parasitaemia-positive 3 days after the challenge.

In order to capture potential differences in protective efficacy offered by $s 20(-)$ and WT $\gamma \mathrm{spz}$, we next employed a suboptimal immunization schedule consisting of only two doses of $10,000 s 20(-)$ or WT $\gamma \mathrm{spz}$, which has been demonstrated to induce incomplete protection (Friesen and Matuschewski, 2011). Immunized mice were challenged by intravenous injection of 10,000 WT sporozoites 35 days after the last immunization (Figure 4A). Control mice became blood stage positive on day 3 after challenge inoculation. Challenge infections of $s 20(-) \gamma \mathrm{spz}-$ immunized mice resulted in blood stage parasites in 4 of 10 immunized mice with a mean pre-patent period of 8 days, whereas 3 of 9 WT $\gamma$ spz-immunized mice became positive for blood stage parasitaemia with a mean pre-patent period of 7 days (Figure $4 \mathbf{A}$ ). To independently confirm the results, we performed a second immunization experiment involving single- and two dose-immunization schedule, and quantified parasite loads in the liver $48 \mathrm{~h}$ after challenge with 10,000 WT sporozoites by qRT-PCR (Figure 4B). In this analysis we also could not detect any differences between the relative parasite loads in livers of $s 20(-)$ and WT $\gamma$ spz-immunized mice. Together, these findings suggest that the $\mathrm{S} 20_{318-326}$ reactive $\mathrm{CD}^{+} \mathrm{T}$ cell population does not contribute markedly to vaccineinduced protection.

\section{Lack of $\mathrm{S}^{2} \mathrm{O}_{318-326}$-Specific CD8 ${ }^{+} \mathrm{T}$ Cells in s20(-) Sporozoite-Immunized Mice}

Finally, we wanted to unequivocally confirm that the cells in immunized mice that recognize the S20 peptide VNYSFLYLF were stimulated by this epitope in PbS20. Therefore, we performed fluorescence-activated cell sorting (FACS) analysis and ELISPOT assays to detect restimulated peptide-specific splenic $\mathrm{CD}^{+} \mathrm{T}$ cells from $\gamma \mathrm{spz}$-immunized mice (Figure 5 and Supplementary Figure 3). As expected, only background signals of IFN $\gamma$ responses after stimulation with $\mathrm{S} 20_{318-326}$ peptide were detected in naive and s20(-)-immunized mice (Hafalla et al., 2013; Müller et al., 2017). In contrast, activated splenic $\mathrm{CD}^{+} \mathrm{T}$ cells from WT-immunized mice could be restimulated with $\mathrm{S}_{2} \mathrm{O}_{318-326}$ peptide. The cell population responding to the TRAP $130-138$ peptide was noticeably higher, as observed in both WT- and $s 20(-)$-immunized mice. As controls, we included cells from naive B6 mice (Supplementary Figure 4). Together,

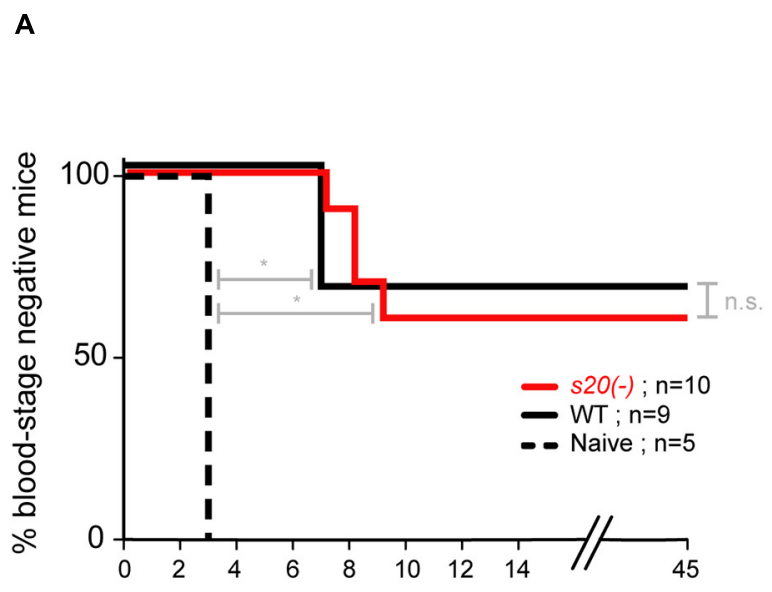

Time (d)

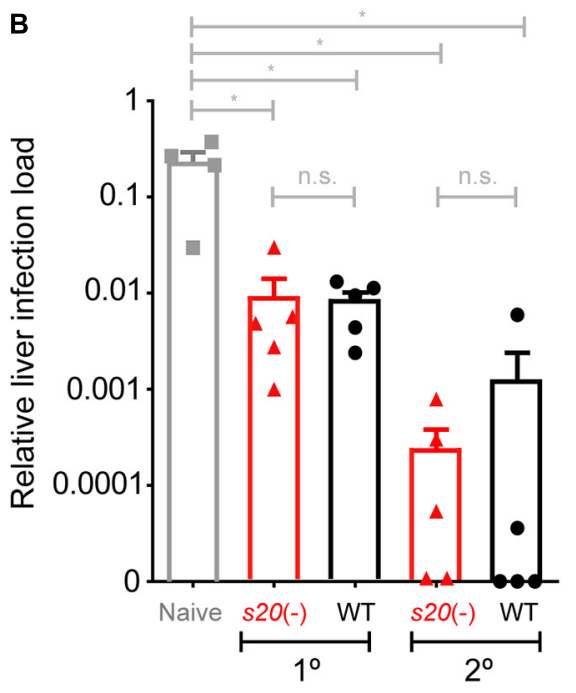

FIGURE 4 | Loss of S20 does not affect vaccine-induced protection. (A) Immunization and challenge protocol. Groups of B6 mice were immunized twice with 10,000 s20(-) $(n=10)$ or WT $\gamma$-sporozoites $(n=9)$ and challenged 35 days after the last immunization by intravenous injection of 10,000 WT sporozoites. Naïve mice $(n=5)$ served as a control. Shown is a Kaplan-Meier analysis of time to blood infection after challenge infection. From day 3 onward mice were monitored daily for blood stage parasitaemia by microscopic examination of Giemsa-stained blood films. n.s., non-significant; ${ }^{*} p<0.05$ (Mann Whitney $U$ test). (B) Protective efficacy as measured by qRT-PCR. S20(-) and WT single or double immunized were challenged with 10,000 infectious sporozoites ( $n=5$ each). Naive mice ( $n=4)$ served as controls. The relative liver load was determined $42 \mathrm{~h}$ later after liver removal, RNA extraction and qRT-PCR with Pb18S rRNA primers normalized to mouse GAPDH. Shown are mean values ( \pm SEM); $n=1$. 


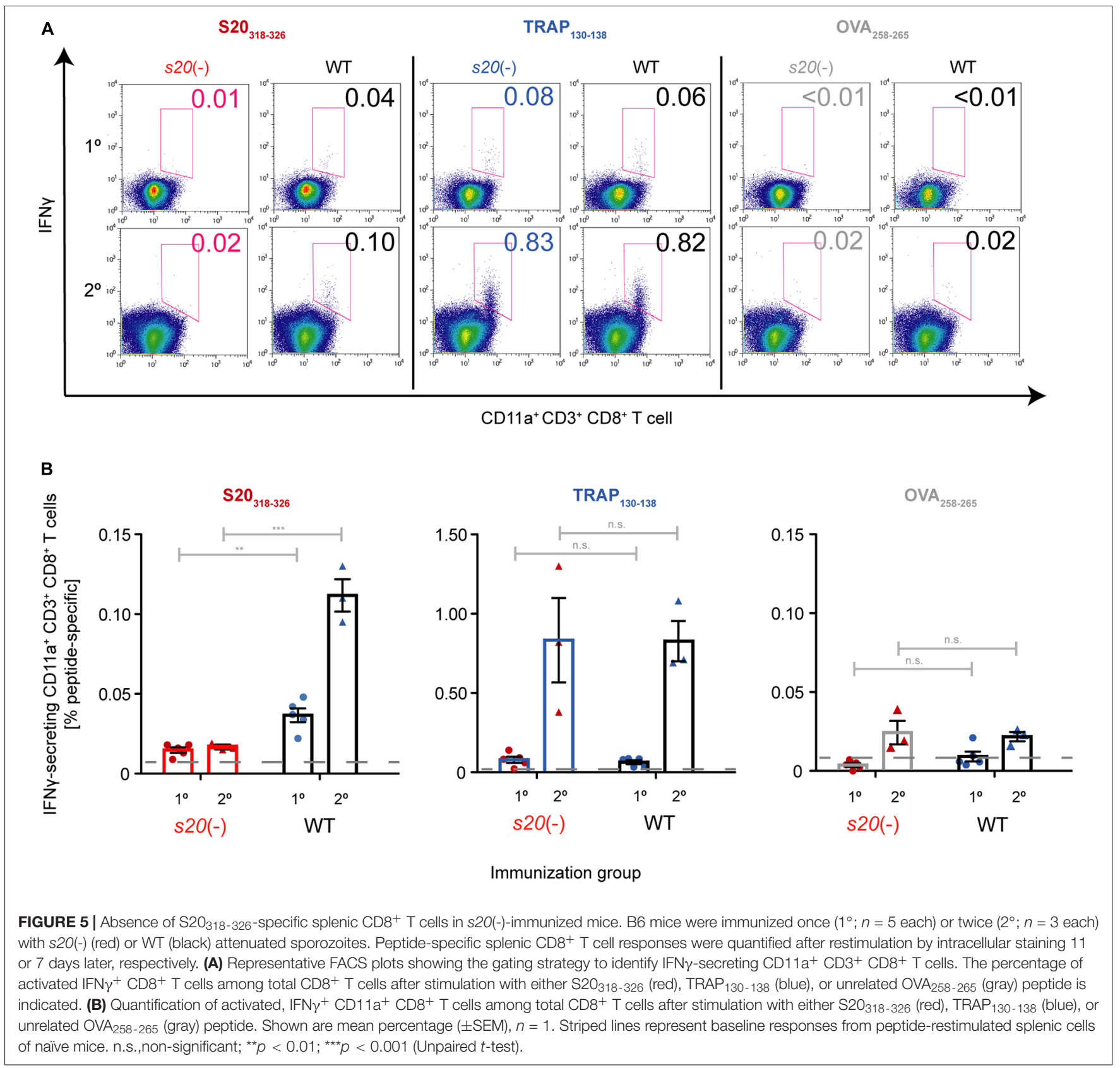

these results show that the $\mathrm{S}_{20} 0_{318-326}$ specific responses can be attributed to the presence of $\mathrm{PbS} 20$ in sporozoites used for immunization.

\section{DISCUSSION}

In this study, we deleted a previously identified $\mathrm{CD}^{+} \mathrm{T}$ cell reactive epitope together with its corresponding gene, the sporozoite-specific protein S20 (PBANKA_1429200) (Kaiser et al., 2004; Hafalla et al., 2013; Müller et al., 2017). Validating candidate antigens recognized by $\mathrm{CD}^{+} \mathrm{T}$ cells is an important aspect toward a mechanistic understanding of immune responses. As an example, previous work on identification of reactive $\mathrm{CD}^{+} \mathrm{T}$ cells in a transgenic mouse model, so called $P b$ T-1 cells, erroneously assigned the reactive peptide to PBANKA_0714500 (Lau et al., 2014) to later correct this to the ribosomal protein RPL6 (Valencia-Hernandez et al., 2020). Here, we could assign the $\mathrm{CD}^{+}{ }^{+} \mathrm{T}$ cell-reactive, H2$\mathrm{K}^{b}$-restricted epitope VNYSFLYFL to $P$. berghei S20. Since we also wanted to explore the cellular function of $\mathrm{PbS} 20$ we employed double homologous recombination to delete the entire gene locus. We could show that $s 20(-)$ parasites progress normally through the $P$. berghei life cycle and induce typical exponential blood infections when animals are inoculated with $s 20(-)$ sporozoites. This was surprising considering the degree 
of conservation of S20 across the genus Plasmodium. The WT-like sporozoite signatures, including gliding motility, liver infectivity, and prepatency permitted us to directly compare vaccine efficacy of $s 20(-) \gamma \mathrm{spz}$ in comparison to WT $\gamma \mathrm{spz}$. Despite the absence of $\mathrm{S}_{2} \mathrm{O}_{318-326}$-reactive, IFN $\gamma$-secreting $\mathrm{CD}^{+} \mathrm{T}$ cells we could not detect differences in $\gamma \mathrm{spz}$-induced protective efficacy in double or triple immunization protocols. An attractive hypothesis is that sporozoites express the immunogenic S20 as a decoy to divert protective immune responses from sporozoites and developing liver stages. In support of this notion, prior studies investigating the $P$. berghei $\mathrm{S}_{20} 0_{318-326}$ epitope uncovered a surprising lack of in vivo cytotoxicity of S20 $318-326^{-s p e c i f i c ~ C D}{ }^{+} \mathrm{T}$ cells (Hafalla et al., 2013) and an inability of $\mathrm{S}_{2} \mathrm{O}_{318}-326^{-}$-specific responses to confer protection in mice (Doll et al., 2016). In marked contrast, TRAP $130-138^{-}$ specific $\mathrm{CD}^{+} \mathrm{T}$ cells are cytotoxic, and subunit immunization strategies against PbTRAP elicit protective immunity (Hafalla et al., 2013; Doll et al., 2016). The presence of a similar protein in T. gondii, which however lacks the $\mathrm{CD}^{+} \mathrm{T}$ cell epitope under investigation, hints at a potential alternative hypothesis. S20 could be a remnant apicomplexan sporozoite protein, which no longer exerts a central role in Plasmodium sporozoites. We consider this possibility less likely due to the high degree of conservation. Experimental genetics studies in coocidian parasites are warranted to determine the role of the kelchcontaining proteins in these parasites and infer a potential loss of function in Haemosporidae.

Identifying immunogenic targets of protective immunity against Plasmodium infection remains a priority in malaria research. Early work with $\gamma \mathrm{spz}$ immunizations has established that protracted, sterilizing pre-erythrocytic protection can be largely attributed to memory effector $\mathrm{CD}^{+}{ }^{+} \mathrm{T}$ cells (Schofield et al., 1987; Weiss et al., 1988; Guebre-Xabier et al., 1999; Krzych et al., 2000; Schmidt et al., 2008). However, robust protection cannot be directly inferred from the magnitude of epitope-specific IFN $\gamma^{+} \mathrm{CD}^{+} \mathrm{T}$ cell populations (Hafalla et al., 2013; Kimura et al., 2013; Müller et al., 2021). For instance, heterologous prime-boost immunizations with TRAPexpressing adenovirus and Modified Vaccinia Ankara (Ad-M) generated very high levels of $\mathrm{TRAP}_{130-138}$-reactive effector $\mathrm{CD}^{+} \mathrm{T}$ cells in $\mathrm{H} 2-\mathrm{K} / \mathrm{D}^{b}$ - restricted $\mathrm{B} 6$ mice, but provided only partial protection against sporozoite challenge infections (Hafalla et al., 2013). On the other hand, rendering the OVA $_{258-265}$ model epitope poorly immunogenic by placing it in the context of a liver stage antigen still resulted in efficient killing of parasite-infected cells by vaccination (Müller et al., 2021). In the $\mathrm{H} 2-\mathrm{K}^{d}$-restricted BALB/c model vaccine efficacy can be largely predicted by the magnitude of $\mathrm{CD}^{+} \mathrm{T}$ cells reactive to the immunodominant CSP-specific epitope (SYVPSAEQI) (Bruña-Romero et al., 2001; GonzálezAseguinolaza et al., 2003). Hence, in order to design subunit vaccine strategies that are as potent as the protracted sterile protection induced by $\gamma \mathrm{spz}$, many factors including specificity of $\mathrm{CD}^{+} \mathrm{T}$ cell responses and magnitude of responses have to be considered.

To date, most targets of $\gamma \mathrm{spz}$-induced $\mathrm{CD}^{+} \mathrm{T}$ cells are likely either poorly defined or remain unrecognized, and whether $\gamma \mathrm{spz}$-induced protection requires presentation of many or just a few pre-erythrocytic stage epitopes remains unclear. Previous work has focused on identifying and investigating individual $\mathrm{CD}^{+} \mathrm{T}$ cell epitopes using subunit vaccine strategies (BruñaRomero et al., 2001; Hafalla et al., 2013; Doll et al., 2016), but the reverse approach, to test whether individual epitopes are required for sterile immunity offered by $\gamma \mathrm{spz}$, remains largely unexplored. Previous studies have demonstrated the ability to elicit sterile immunity in $\mathrm{H}-2 \mathrm{~K}^{d}$-restricted $\mathrm{BALB} / \mathrm{c}$ mice in the absence of CSP-specific responses (Grüner et al., 2007; Gibbins et al., 2020). The findings suggested that sterile protection does not necessarily depend on CSP-reactive CD8 ${ }^{+}$ $\mathrm{T}$ cells, and indicated that inclusion of additional, non-CSP epitopes to subunit vaccine strategies is warranted. Another important stepping stone toward a better understanding of the underlying mechanisms of vaccine-induced protection is distinction of protective from non-protective epitopes by experimental genetics, as exemplified in this study.

Sterile immunity offered by $\gamma \mathrm{spz}$ in the absence of $S 20$ clearly suggests that S20 is not a promising malaria vaccine candidate, fully supporting the findings that prime-boost immunization against $\mathrm{S}_{20} \mathrm{O}_{318-326}$ epitope in mice did not elicit sterilizing immunity despite robust $\mathrm{CD}^{+} \mathrm{T}$ cell responses (Doll et al., 2016). For viral infections, compensatory $\mathrm{CD} 8^{+} \mathrm{T}$ cell responses were shown to be induced by subdominant epitopes when immunodominant epitope-specific effector $\mathrm{CD}^{+} \mathrm{T}$ cells are absent (Rodriguez et al., 2002; van der Most et al., 2003). Apparently, immunosuppressive effects of IFN $\gamma$ secreted in large amounts by dominant $\mathrm{CD} 8^{+} \mathrm{T}$ cell responses are abolished, thus allowing subdominant epitope-specific precursor $\mathrm{CD}^{+} \mathrm{T}$ cells to proliferate. As a result, the subdominance is alleviated and compensatory responses are generated without suppression by IFN $\gamma$. Therefore, IFN $\gamma$ plays a vital role in shaping the epitope immunodominance hierarchy, and subdominant epitopes are key players in inducing these compensatory responses in the absence of immunodominant epitopes. Together, the absence of the subdominant $\mathrm{S}_{2} \mathrm{O}_{318-326}$ epitope in $P$. berghei, as demonstrated by inferior IFN $\gamma$ responses in comparison to TRAP $_{130-138}$, apparently did not result in compensatory responses generated toward other $\mathrm{CD}^{+} \mathrm{T}$ cell epitopes. Hence, maintenance of sterile protection observed in the absence of S20-specific responses was achieved by the sum of all $\gamma \mathrm{spz}-$ induced responses other than $\mathrm{S} 20318-326_{3}$. This hypothesis can be experimentally addressed by a similar strategy as presented herein, by removal of the dominant $\mathrm{H} 2-\mathrm{D}^{b}$-restricted TRAP $_{130-138} \mathrm{CD}^{+} \mathrm{T}$ cell epitope.

The anti-PbS20 peptide antiserum detected a cytoplasmic location of S20 in sporozoites and very early liver stages. The effect of antigen localization on protective immunity was also examined with the model antigen ovalbumin (OVA) in transgenic $P$. berghei-expressing exported or nonexported OVA (Montagna et al., 2014). P. berghei parasites expressing secreted OVA were found to enhance $\mathrm{CD}^{+}$ $\mathrm{T}$ cell proliferation and MHC I presentation by infected hepatocytes during immunization, resulting in improved liver stage clearance following homologous sporozoite challenge. Importantly, large differences in immunogenicity 
due to antigen origin in malaria pre-erythrocytic stages are overcome by robust recognition by vaccine-induced, antigen-specific effector $\mathrm{CD}^{+} \mathrm{T}$ cells, leading to comparable high levels of protection (Müller et al., 2021). Hence, although intracellular antigens might have marginal impacts on the level of $\mathrm{CD}^{+} \mathrm{T}$ cell responses to whole sporozoite immunization, immunogenic $\mathrm{CD}^{+} \mathrm{T}$ cell epitopes derived from intracellular proteins should not be disregarded as potential candidates in subunit vaccine design.

In conclusion, our results revealed a non-vital role of $\$ 20$ in Plasmodium life cycle progression in vivo and surrogate cell culture assays, despite being a highly conserved gene across all Plasmodium species. Protective immunity from $s 20(-) \gamma s p z$ immunizations was similar to WT $\gamma$ spz. Our findings exemplify that malarial parasites express conserved, immunogenic proteins that are not required to establish infection in a new mammalian host but might play potential roles in diverting cellular immune responses. Molecular and immunological characterization of candidate Plasmodium antigens can assist in prioritizing candidates for urgently needed second-generation malaria vaccines.

\section{MATERIALS AND METHODS}

\section{Ethics Statement}

All animal work was conducted in accordance with the German "Tierschutzgesetz in der Fassung vom 18. Mai 2006 (BGBl. I S. 1207)," which implements the directive 86/609/EEC from the European Union and the European Convention for the protection of vertebrate animals used for experimental and other scientific purposes. The ethics committee of MPI-IB and the Berlin state authorities (LAGeSo Reg\# G0469/09 and G0294/15) approved the protocol.

\section{Parasites and Experimental Animals}

Plasmodium berghei ANKA cl507 parasites that constitutively express GFP under the PbEF1a promoter were used in our experiments (Franke-Fayard et al., 2004). Six- to Eight-weeks old female NMRI and SWISS or B6 mice used in this study were either purchased from Charles River Laboratories or bred in-house. NMRI mice were used for transfection experiments, blood stage infections and transmission to Anopheles stephensi mosquitos. B6 mice were used for sporozoite infections and subsequent immunological studies.

\section{Targeted Gene Deletion and Expression of $\mathbf{S 2 0}$}

The P. berghei S20 gene was deleted by a double homologous recombination strategy using a standard replacement knockout plasmid (pB3D; van Dijk et al., 1995). For this aim, fragments from the $5^{\prime}$ and $3^{\prime}$ ends were amplified with primers S20SacII and S20NotI, and with the primer pair S20HindIII and S20KpnI using PCR. Subsequently, the $5^{\prime}$ PCR fragment was double digested overnight at $37^{\circ} \mathrm{C}$ with the restriction enzymes SacII and NotI, while the restriction enzymes HindIII and KpnI were used for the $3^{\prime}$ fragment digestion. $10 \mu \mathrm{g}$ plasmid was linearized with SacII and KpnI for transfection. Transfection experiments were carried out twice, as previously described (Janse et al., 2006), to obtain two independent clones for phenotypical analysis; clone 3 and 4. Successful integration was tested on genomic DNA by conventional PCR using the primers Test1S20fw and JFUTRrv for $5^{\prime}$ integration, and TgPro and Test2S20rv for $3^{\prime}$ integration. Absence of WT parasites in the clonal population was verified using Test1S20fw and Test2S20rv primers. The PCR was carried out as follows: Initial denaturation for $3 \mathrm{~min}$ at $94^{\circ} \mathrm{C}$, followed by 35 cycles of $30 \mathrm{~s}$ denaturation at $94^{\circ} \mathrm{C}$, annealing for $45 \mathrm{~s}$ at $55^{\circ} \mathrm{C}$, and extension at $60^{\circ} \mathrm{C}$ for $2 \mathrm{~min}$ 30 s. A final extension was carried out for $10 \mathrm{~min}$ at $60^{\circ} \mathrm{C}$. For studying the expression of $S 20$ during the $P$. berghei life cycle, amplification was performed by qPCR with the primers qS20fw and qS20rv on cDNA of midgut sporozoites, salivary gland sporozoites, early liver stages, late liver stages, mixed blood stages and gametocytes obtained from P. berghei ANKA cl507 parasites, which constitutively express GFP under the PbEF1 $1 \alpha$ promoter (Janse et al., 2006). Expression levels were normalized to the GFP transcript levels determined by primers qGFPfw and qGFPrv.

\section{Salivary Gland Sporozoite Isolation}

Wild-type GFP-expressing P. berghei ANKA and P. berghei s20(-) strains were maintained by continuous cycling between rodent hosts (B6 or NMRI and SWISS mice) and female A. stephensi mosquito vectors (Vanderberg, 1975). Mosquitoes were kept at $28^{\circ} \mathrm{C}$ (non-infected) or $20^{\circ} \mathrm{C}$ (infected) at $80 \%$ humidity. After 10-14 days, midguts were isolated and oocyst development analyzed by fluorescent microscopy. Salivary gland sporozoites were isolated from mosquitos in DMEM medium containing 10\% fetal calf serum (FCS).

\section{Polyclonal Anti-S20 Antibody Generation}

Polyclonal antibodies against S20 were raised in rabbits immunized with synthetic peptides (MSDISDFSDIDDFSE+C and C+TFTSKKLTENPGKRAY) (Eurogentec, Seraing, Belgium).

\section{Immunofluorescence Staining of Salivary Gland Sporozoites}

The gliding motility of salivary gland sporozoites was evaluated by IFA. 5,000 WT or $s 20(-)$ salivary gland sporozoites suspended in 3\% BSA-RPMI were added into each ring of a Medco glass slide pre-coated with $3 \%$ BSA-RPMI. The sporozoites were incubated for $45 \mathrm{~min}$ at $37^{\circ} \mathrm{C}$, during which the parasites glide and shed surface proteins into the extracellular environment. To visualize gliding motility, sporozoites and trails of shed proteins were stained with mouse anti-sporozoite surface antibody, followed by anti-mouse Alexa Fluor 488-coupled antibody (Invitrogen, Carlsbad, CA, United States) and the nuclei stain Hoechst 33342 (Invitrogen, Carlsbad, CA, United States) Slides were mounted with Fluoromount-G (SouthernBiotech) prior to analysis by fluorescence microscopy using Zeiss Axio Imager Z2. To detect S20 by immunofluorescence, sporozoites were 
fixed in 3\% PFA and permeabilized as indicated with $0.3 \%$ Triton X-100 prior to staining with custom-made anti-S20 peptide antiserum or monoclonal anti-CSP (3D11) antibody (Yoshida et al., 1980), and Hoechst 33342 (Invitrogen, Carlsbad, CA, United States).

\section{Hepatoma Cell Infection in vitro and Immunofluorescence Staining}

Nunc Lab-Tek II 8-well Chamber Slides (Thermo Fisher Scientific, New York, NY, United States) were seeded with 30,000 Huh7 cells per well 24 h before infection. 10,000 WT or $s 20(-)$ salivary gland sporozoites suspended in $100 \mu \mathrm{l}$ DMEMcomplete were added and allowed to settle for $1 \mathrm{~h}$ at RT. $P$. berghei S20 was immunostained to investigate the expression of S20 during liver stage development. Here, infected hepatoma cells were incubated at $37^{\circ} \mathrm{C}$ for 1 and $3 \mathrm{~h}$ after infection prior to fixation with $4 \%$ paraformaldehyde and staining with monoclonal anti-HSP70 antibody (Tsuji et al., 1994), anti-S20 peptide antiserum, and Hoechst 33342 (Invitrogen, Carlsbad, CA, United States). Phenotypic analysis of parasite liver stage development was monitored by IFA in Huh7 cells 48 h postinfection at $37^{\circ} \mathrm{C}$. The infected cells were permeabilized with $0.2 \%$ Triton-X 100 (Roth, Karlsruhe, Germany) and analyzed $48 \mathrm{~h}$ later after fixation with $4 \%$ PFA by staining with mouse anti-HSP70 antibody (Tsuji et al., 1994) followed by goat anti-mouse Alexa Fluor 488 antibody (Invitrogen, Carlsbad, CA, United States) and Hoechst 33342 (Invitrogen, Carlsbad, CA, United States). Slides were mounted with Fluoromount-G (SouthernBiotech) and imaged by fluorescence microscopy (Zeiss Axio Imager Z2). At least 20 intracellular parasites per sample were visualized.

\section{s20(-) Parasite Infectivity in vivo}

To determine the infectivity of sporozoites, B6 mice were infected intravenously with either 10,000 WT or $s 20(-)$ salivary gland sporozoites suspended in $100 \mu \mathrm{l}$ PBS per mouse. Simultaneously, another group of B6 mice were infected through direct bites from WT or s20(-)-infected A. stephensi mosquitos for $20 \mathrm{~min}$. In order to confirm the number of mosquitos that received a blood meal, the mosquitos were paralyzed briefly at $-20^{\circ} \mathrm{C}$ and observed for blood in the abdomen under a compound microscope. The pre-patent period was determined by daily microscopic examination of Giemsa-stained blood smears.

\section{Quantification of Parasite Development in vivo}

To rule out a defect of $s 20(-)$ parasites during liver stage development and to determine protective outcome of immunized mice against homologous sporozoite challenge, P. berghei 18S rRNA level during liver stage infection was quantified. Naïve B6 mice were inoculated with either 10,000 WT or s20(-) sporozoites intravenously for phenotypic characterization, and in the sterile protection experiment, female B6 mice were challenged with 10,000 WT sporozoites 35 days after the last immunization. $42 \mathrm{~h}$ after infection, the mice were sacrificed and livers were removed to isolate total RNA using Qiagen RNeasy kit, followed by reverse transcription of the RNA using RETROscript kit. Quantitative Real-Time PCR was performed on cDNA samples using $\mathrm{Pb} 18 \mathrm{~S}$ ribosomal subunit primer pairs (Gene ID: 160641; sense and antisense primers), mouse GAPDH primer pairs (Gene ID: 281199965; sense primer and antisense primers). Relative liver infection loads were then determined using the $\Delta \mathrm{C}_{t}$ method as previously described (Friesen et al., 2010).

\section{Immunization With Attenuated WT and s20(-) Sporozoites}

Salivary gland sporozoites were attenuated either by a $\gamma$ irradiation dose of $12 \times 10^{4} \mathrm{cGy}$, or with azithromycin (AZ) cover $(4.8 \mathrm{mg}$ in $200 \mu \mathrm{l}$ of sodium chloride solution per mouse) (Friesen et al., 2010). For challenge experiments, B6 mice were immunized with two and three doses of WT and $s 20(-) \gamma s p z$. Immunizations in the two-dose regimen with 10,000 sporozoites were carried out on day 0 and 7 . Challenge with 10,000 sporozoites was on day 42 , including an addition of 5 age-matched naïve B6 mice. The priming dose of the three-dose regimen consisted of 15,000 sporozoites, while the subsequent two boosts comprised of 10,000 sporozoites. The immunization doses were given at days 0,35 , and 55 , followed by a challenge with 10,000 WT sporozoites on day 84 , including three naïve animals. All mice were checked for parasitemia by microscopical examination of Giemsa-stained blood smears starting at day 3 after challenge inoculation until day 14. Those animals that remained parasitemia-free were continuously checked for parasitemia up till 45 days after the challenge.

\section{Quantification of $\mathrm{S}^{2} \mathrm{O}_{318-326}$-Specific Splenic CD8 ${ }^{+} \mathbf{T}$ Cells in Immunized Mice}

Each B6 mouse in immunological studies was immunized intravenously with attenuated sporozoites resuspended in $1 \times$ PBS via the lateral tail vein. FACS after restimulation and staining was done to determine the absence of $\mathrm{S}_{20} \mathrm{O}_{318}-326$-specific splenic $\mathrm{CD}^{+} \mathrm{T}$ cell responses. B6 mice were immunized with either a single-dose of 15,000 AZ-attenuated sporozoites, or twodose regimen of $\gamma \mathrm{spz}$ followed by AZ-attenuated sporozoites carried out on day 0 and 7 , respectively, where each dose consisted of 10,000 sporozoites. B6 mice used in enzymelinked immune absorbent spot (ELISPOT) experiments were immunized twice with irradiated $s 20(-)$ or WT irradiated sporozoites at days 0 and 7. Another two groups were immunized in parallel at day 7. Sixteen days after the last immunization, animals were challenged with 10,000 sporozoites, including five naïve mice. $42 \mathrm{~h}$ after challenge mouse spleens were used to extract $\mathrm{CD}^{+} \mathrm{T}$ cells and analyzed for their capacity to induce IFN $\gamma$ responses specific for $\mathrm{S}_{2} 0_{318-326}$ and $\mathrm{TRAP}_{130-138^{-}}$ specific $\mathrm{CD}^{+}$epitopes.

The peptides VNYSFLYLF $\left(\mathrm{S}_{2} \mathrm{O}_{318-326}\right)$, SALLNVDNL $\left(\right.$ TRAP $\left._{130-138}\right)$ (Hafalla et al., 2013), and SIINFEKL $\left(\mathrm{OVA}_{258-265}\right)$ were synthesized by Peptides \& Elephants (Potsdam, Germany), and reconstituted in DMSO/water (1:1) 
at a concentration of $1 \mathrm{mM}$. Female $\mathrm{B} 6$ mice that received a single-dose or prime-boost sporozoite immunization were dissected 11 and 7 days after last immunization, respectively, along with naïve control animals, to obtain splenic lymphocyte cell suspension using a cell strainer. Red blood cell lysis was then carried out with BD Pharm Lyse ${ }^{\mathrm{TM}}$ lysing buffer (Becton, Dickinson and Company, United States) as described in the manufacturer's protocol. In order to quantify sporozoiteinduced $\mathrm{CD}^{+} \mathrm{T}$ cells, the lymphocytes were restimulated with peptides for 5-6 $\mathrm{h}$ in the presence of Brefeldin A (Invitrogen, Carlsbad, CA, United States), followed by extracellular and intracellular staining procedures specific for CD3, CD11a, CD8a, and IFN $\gamma$ using the following antimouse antibodies; CD3e PE-Cy7 (eBioscience, Inc., San Diego, CA, United States), CD8a PerCP Cy5.5 (eBioscience, Inc., San Diego, CA, United States), CD11a e450 (Invitrogen, United States), and IFN $\gamma$-APC (eBioscience, Inc., San Diego, CA, United States). The cells were analyzed using a BD LSR Fortessa flow cytometer (Becton, Dickinson and Company, United States) and data analysis was performed on FLOWJO software (Becton, Dickinson and Company, United States). Target $\mathrm{CD}^{+} \mathrm{T}$ cells were identified from the gated lymphocyte population by the removal of doublets followed by the exclusion of cell debris, artifacts, and other non-target cells (Supplementary Figure 4B).

To support the findings from FACS analysis, ELISPOTs were also carried out on splenic $\mathrm{CD}^{+}{ }^{+} \mathrm{T}$ cells from immunized female B6 mice (see above) using the same VNYSFLYLF (S20318-326) and SALLNVDNL (TRAP $130-138$ ) (Hafalla et al., 2013) peptides for restimulation. Sterile high protein binding Immobilon-P MultiScreen 96-Well Plate (Millipore, Germany) with $0.45 \mu \mathrm{m}$ pore size were used as ELISPOT plates. Prior to plating of the cells, plates were pre-wet for 1 min with 35\% EtOH, washed with sterile water and incubated overnight with $75 \mu \mathrm{l}$ of rat anti-mouse IFN $\gamma$ antibody (AN-18; rat IgG1; eBioscience) at a concentration of $8 \mu \mathrm{g} / \mathrm{ml}$ in sterile PBS at $4^{\circ} \mathrm{C}$. After washing with sterile PBS, plates were blocked with DMEM containing $10 \%$ FCS and Penicillin/Streptomycin for $2 \mathrm{~h}$ at $37^{\circ} \mathrm{C}$. Splenic cell suspensions from immunized and control animals were prepared using a cell strainer, and red blood cells were lysed with BD Pharm Lyse lysing buffer as described in the manufacturer's protocol. $10^{8}$ cells were used for isolation of $\mathrm{CD}^{+}$cells by positive selection using CD8a (Ly-2) MicroBeads (Miltenyi, Germany) following the manufacturer's instructions. 200,000 $\mathrm{CD}^{+}$cells and the same number of antigen-presenting cells were used per well. Naïve spleen cells were incubated with $2 \mu \mathrm{M}$ peptide for $2 \mathrm{~h}$ at $37^{\circ} \mathrm{C}$. Afterward, antigen-presenting cells were $\gamma$-irradiated for $28 \mathrm{~min}$ and washed twice before co-incubation for at least $20 \mathrm{~h}$ with $\mathrm{CD}^{+} \mathrm{T}$ cells at $37^{\circ} \mathrm{C}$. Plates were washed three times with $1 \times$ PBS and three times with $1 \times$ PBS containing $0.05 \%$ Tween 20 (PBST20), and were subsequently incubated with $100 \mu \mathrm{l}$ PBST20 containing $0.5 \%$ FCS with $1 \mu \mathrm{g} / \mathrm{ml}$ of the biotinylated detection antibody anti-mouse IFN $\gamma \mathrm{mAb}$ R4-6A2 (Mabtech, Germany) overnight at $4^{\circ} \mathrm{C}$. On the following day, plates were washed four times in PBST20 and incubated further for $1 \mathrm{~h}$ at room temperature with streptavidin-conjugated alkaline phosphatase (BD Pharmingen, Germany) in PBST20 containing
$1 \%$ FCS. After washing four times with PBST20 and $1 \times$ PBS, ELISPOT plates were developed using the Bio-Rad AP color development kit until spots were visible, which were then counted using a binocular.

\section{Statistics}

Statistical analysis (see Figure Legends) were performed using Prism software (GraphPad Software Inc., United States).

\section{DATA AVAILABILITY STATEMENT}

The original contributions presented in the study are included in the article/Supplementary Material, further inquiries can be directed to the corresponding author/s.

\section{ETHICS STATEMENT}

The animal study was reviewed and approved by the Ethics Committee of MPI-IB and the Berlin state authorities (LAGeSo Reg\# G0469/09 and G0294/15) approved the protocol.

\section{AUTHOR CONTRIBUTIONS}

$\mathrm{KMa}$, JF, CH, JH, and KMü designed the experiments. $\mathrm{CH}$ and JF performed the experiments and analyzed the data. AI performed and analyzed the sporozoite IFA. DS generated knockout parasite lines. $\mathrm{KMa}, \mathrm{CH}$, and JF wrote the manuscript. All authors commented and revised the manuscript.

\section{FUNDING}

This work was funded by the Deutsche Forschungsgemeinschaft through the research training group-Ph.D. program 2046 "From Experimental Models to Natural Systems" (project B1) and in part by the Max Planck Society.

\section{ACKNOWLEDGMENTS}

We acknowledge support by the German Research Foundation (DFG) and the Open Access Publication Fund of HumboldtUniversität zu Berlin.

\section{SUPPLEMENTARY MATERIAL}

The Supplementary Material for this article can be found online at: https://www.frontiersin.org/articles/10.3389/fmicb.2021. 703804/full\#supplementary-material 


\section{REFERENCES}

Altschul, S. F., Gish, W., Miller, W., Myers, E. W., and Lipman, D. J. (1990). Basic local alignment search tool. J. Mol. Biol. 215, 403-410. doi: 10.1016/S00222836(05)80360-2

Aurrecoechea, C., Barreto, A., Basenko, E. Y., Brestelli, J., Brunk, B. P., Cade, S., et al. (2017). EuPathDB: the eukaryotic pathogen genomics database resource. Nucl. Acids Res. 45 (D1), D581-D591. doi: 10.1093/nar/gkw1105

Bork, P., and Doolittle, R. F. (1994). Drosophila kelch motif is derived from a common enzyme fold. J. Mol. Biol. 236, 1277-1282. doi: 10.1016/0022-2836(94) 90056-6

Bruña-Romero, O., González-Aseguinolaza, G., Hafalla, J. C. R., Tsuji, M., and Nussenzweig, R. S. (2001). Complete, long-lasting protection against malaria of mice primed and boosted with two distinct viral vectors expressing the same plasmodial antigen. Proc. Natl. Acad. Sci. U.S.A. 98, 11491-11496. doi: 10.1073/pnas.191380898

Butler, N. S., Schmidt, N. W., and Harty, J. T. (2010). Differential effector pathways regulate memory CD8 T cell immunity against Plasmodium berghei versus $\mathrm{P}$. yoelii sporozoites. J. Immunol. 184, 2528-2538. doi: 10.4049/jimmunol.0903529

Clyde, D. F., Most, H., McCarthy, V. C., and Vanderberg, J. P. (1973). Immunization of man against sporozoite-induced falciparum malaria. Am. J. Med. Sci. 266, 169-177. doi: 10.1097/00000441-197309000-00002

Cohen, J., Nussenzweig, V., Nussenzweig, R., Vekemans, J., and Leach, A. (2010). From the circumspo-rozoite protein to the RTS, S/AS candidate vaccine. Hum. Vaccin. 6, 90-96. doi: 10.4161/hv.6.1.9677

Depinay, N., Franetich, J. F., Grüner, A. C., Mauduit, M., Chavatte, J. M., Luty, A. J. F., et al. (2011). Inhibitory effect of TNF- $\alpha$ on malaria pre-erythrocytic stage development: Influence of host hepato-cyte/parasite combinations. PLoS One 6:e17464. doi: 10.1371/journal.pone.0017464

Doll, K. L., Pewe, L. L., Kurup, S. P., and Harty, J. T. (2016). Discriminating protective from non-protective Plasmodium-specific CD8+ T cell responses. J. Immunol. 196, 4253-4262. doi: 10.4049/jimmunol.1600155

Doolan, D. L., and Hoffman, S. L. (2000). The complexity of protective immunity against liver-stage ma-laria. J. Immunol. 165, 1453-1462. doi: 10. 4049/jimmunol.165.3.1453

Ferreira, A., Schofield, L., Enea, V., Schellekens, H., van der Meide, P., Collins, W., et al. (1986). Inhibition of development of exoerythrocytic forms of malaria parasites by gamma-interferon. Science 232, 881-884. doi: 10.1126/science. 3085218

Franke-Fayard, B., Trueman, H., Ramesar, J., Mendoza, J., van der Keur, M., van der Linden, R., et al. (2004). A Plasmodium berghei reference line that constitutively expresses GFP at a high level throughout the complete life cycle. Mol. Biochem. Parasitol. 137, 23-33. doi: 10.1016/j.molbiopara.2004.04.007

Friesen, J., and Matuschewski, K. (2011). Comparative efficacy of pre-erythrocytic whole organism vaccine strategies against the malaria parasite. Vaccine 29, 7002-7008. doi: 10.1016/j.vaccine.2011.07.034

Friesen, J., Silvie, O., Putrianti, E. D., Hafalla, J. C. R., Matuschewski, K., and Borrmann, S. (2010). Natural immunization against malaria: causal prophylaxis with antibiotics. Sci. Transl. Med. 2:ra49. doi: 10.1126/scitranslmed.3001058

Gibbins, M. P., Müller, K., Glover, M., Liu, J., Putrianti, E. D., Bauza, K., et al. (2020). Importance of the immunodominant CD8+ T cell epitope of Plasmodium berghei circumsporozoite protein in parasite- and vaccine-induced protection. Infect. Immun. 88, e383-20. doi: 10.1128/IAI.00383-20

González-Aseguinolaza, G., Nakaya, Y., Molano, A., Dy, E., Esteban, M., Rodríguez, D., et al. (2003). Induction of protective immunity against malaria by priming-boosting immunization with recombinant cold-adapted influenza and modified vaccinia Ankara viruses expressing a CD8+-T-cell epitope derived from the circumsporozoite protein of Plasmodium yoelii. J. Virol. 77, 1185911866. doi: 10.1128/jvi.77.21.11859-11866.2003

Grüner, A. C., Mauduit, M., Tewari, R., Romero, J. F., Depinay, N., Kayibanda, M., et al. (2007). Sterile protection against malaria is independent of immune responses to the circumsporozoite protein. PLoS One 2:e1371. doi: 10.1371/ journal.pone.0001371

Guebre-Xabier, M., Schwenk, R., and Krzych, U. (1999). Memory phenotype CD8+ $\mathrm{T}$ cells persist in livers of mice protected against malaria by immunization with attenuated Plasmodium berghei sporozoites. Eur. J. Immunol. 29, 3978-3986. doi: 10.1002/(sici)1521-4141(199912)29:12<3978::aid-immu3978>3.0.co;2-0
Hafalla, J. C., Silvie, O., and Matuschewski, K. (2011). Cell biology and immunology of malaria. Immunol. Rev. 240, 297-316. doi: 10.1111/j.1600-065X.2010. 00988.x

Hafalla, J. C. R., Bauza, K., Friesen, J., Gonzalez-Aseguinolaza, G., Hill, A. V. S., and Matuschewski, K. (2013). Identification of targets of CD8+ T cell responses to malaria liver stages by genome-wide epitope profiling. PLoS Pathogens 9:e1003303. doi: 10.1371/journal.ppat.1003303

Hoffman, S. L., Billingsley, P. F., James, E., Richman, A., Loyevsky, M., Li, T., et al. (2010). Development of a metabolically active, non-replicating sporozoite vaccine to prevent Plasmodium falciparum malaria. Hum. Vaccin. 6, 97-106. doi: 10.4161/hv.6.1.10396

Hoffman, S. L., Goh, L. M., Luke, T. C., Schneider, I., Le, T. P., Doolan, D. L., et al. (2002). Protection of humans against malaria by immunization with radiation-attenuated Plasmodium falciparum sporozoites. J. Infect. Dis. 185, 1155-1164.

Janse, C. J., Franke-Fayard, B., Mair, G. R., Ramesar, J., Thiel, C., Engelmann, S., et al. (2006). High efficiency transfection of Plasmodium berghei facilitates novel selection procedures. Mol. Biochem. Parasitol. 145, 60-70. doi: 10.1016/j. molbiopara.2005.09.007

Kaiser, K., Matuschewski, K., Camargo, N., Ross, J., and Kappe, S. H. (2004). Differential transcriptome profiling identifies Plasmodium genes encoding preerythrocytic stage-specific proteins. Mol. Microbiol. 51, 1221-1232. doi: 10. 1046/j.1365-2958.2003.03909.x

Kimura, K., Kimura, D., Matsushima, Y., Miyakoda, M., Honma, K., Yuda, M., et al. (2013). CD8+ T cells specific for a malaria cytoplasmic antigen form clusters around infected hepatocytes and are protective at the liver stage of infection. Infect. Immun. 81, 3825-3834. doi: 10.1128/IAI.00570-13

Krzych, U., Schwenk, R., Guebre-Xabier, M., Sun, P., Palmer, D., White, K., et al. (2000). The role of intrahepatic lymphocytes in mediating protective immunity by attenuated Plasmodium berghei sporozoites. Immunol. Rev. 174, 123-134. doi: 10.1034/j.1600-0528.2002.00013h.x

Kumar, K. A., Sano, G., Boscardin, S., Nussenzweig, R. S., Nussenzweig, M. C., Zavala, F., et al. (2006). The circumsporozoite protein is an immunodominant protective antigen in irradiated sporozoites. Nature 444, 937-940. doi: 10.1038/ nature05361

Lau, L. S., Fernandez-Ruiz, D., Mollard, V., Sturm, A., Neller, M. A., Cozijnsen, A., et al. (2014). CD8+ T cells from a novel T cell receptor transgenic mouse induce liver-stage immunity that can be boosted by blood-stage infection in rodent malaria. PLoS Pathogens 10:e1004135. doi: 10.1371/journal.ppat.1004135

Montagna, G. N., Beigier-Bompadre, M., Becker, M., Kroczek, R. A., Kaufmann, S. H. E., and Matuschewski, K. (2014). Antigen export during liver infection of the malaria parasite augments protective immunity. mBio 5:e1321-14. doi: 10.1128/mBio.01321-14

Müller, K., Gibbins, M. P., Matuschewski, K., and Hafalla, J. C. R. (2017). Evidence of cross-stage CD8+ T cell epitopes in malaria pre-erythrocytic and blood stage infections. Parasite Immunol. 39:e12434. doi: 10.1111/pim.12434

Müller, K., Gibbins, M. P., Roberts, M., Reyes-Sandoval, A., Hill, A. V. S., Draper S. J., et al. (2021). Low immunogenicity of malaria pre-erythrocytic stages can be overcome by vaccination. EMBO Mol. Med. 13:e13390. doi: 10.15252/ emmm. 202013390

Neafsey, D. E., Juraska, M., Bedford, T., Benkeser, D., Valim, C., Griggs, A., et al. (2015). Genetic diversity and protective efficacy of the RTS,S/AS01 malaria vaccine. N. Engl. J. Med. 373, 2025-2037. doi: 10.1056/nejmoa1505819

Nussenzweig, R. S., Vanderberg, J., Most, H., and Orton, C. (1967). Protective immunity produced by the injection of $\mathrm{x}$-irradiated sporozoites of Plasmodium berghei. Nature 216, 160-162. doi: 10.1038/216160a0

Richie, T. L., Billingsley, P. F., Sim, B. K. L., James, E. R., Chakravarty, S., Epstein, J. E., et al. (2015). Progress with Plasmodium falciparum sporozoite (PfSPZ)based malaria vaccines. Vaccine 33, 7452-7461. doi: 10.1016/j.vaccine.2015.09. 096

Rodrigues, M., Nussenzweig, R. S., and Zavala, F. (1993). The relative contribution of antibodies, CD4+ and CD8+ T cells to sporozoite-induced protection against malaria. Immunology 80, 1-5.

Rodrigues, M. M., Cordey, A. S., Arreaza, G., Corradin, G., Romero, P., Maryanski, J. L., et al. (1991). CD8+ cytolytic T cell clones derived against the Plasmodium yoelii circumsporozoite protein protect against malaria. Int. Immunol. 3, 579585. doi: 10.1093/intimm/3.6.579 
Rodriguez, F., Harkins, S., Slifka, M. K., and Whitton, J. L. (2002). Immunodominance in virus-induced CD8+ T-cell responses is dramatically modified by DNA immunization and is regulated by gamma interferon. J. Virol. 76, 4251-4259. doi: 10.1128/jvi.76.9.4251-4259.2002

Romero, P., Maryanski, J. L., Corradin, G., Nussenzweig, R. S., Nussenzweig, V., and Zavala, F. (1989). Cloned cytotoxic T cells recognize an epitope in the circumsporozoite protein and protect against malaria. Nature 341, 323-326. doi: $10.1038 / 341323 \mathrm{a} 0$

RTS,S Clinical Trials Partnership (2015). Efficacy and safety of RTS,S/AS01 malaria vaccine with or without a booster dose in infants and children in Africa: final results of a phase 3, individually randomized, controlled trial. Lancet 386, 31-45. doi: 10.1016/S0140-6736(15)60721-8

Sano, G. I., Hafalla, J. C. R., Morrot, A., Abe, R., Lafaille, J. J., and Zavala, F. (2001). Swift development of protective effector functions in naive CD8+ T cells against malaria liver stages. J. Exp. Med. 194, 173-180. doi: 10.1084/jem.194.2.173

Schmidt, N. W., Podyminogin, R. L., Butler, N. S., Baovinac, V. P., Tucker, B. J., Bahjat, K. S., et al. (2008). Memory CD8 T cell responses exceeding a large but definable threshold provide long-term immunity to malaria. Proc. Natl. Acad. Sci. U.S.A. 105, 14017-14022. doi: 10.1073/pnas.0805452105

Schofield, L., Villaquiran, J., Ferreira, A., Schellekens, H., Nussenzweig, R., and Nussenzweig, V. (1987). $\gamma$ interferon,CD8+ T cells and antibodies required for immunity to malaria sporozoites. Nature 330, 664-666. doi: 10.1038/330664a0

Sedegah, M., Sim, B. K. L., Mason, C., Nutman, T., Malik, A., Roberts, C., et al. (1992). Naturally acquired CD8+ cytotoxic T lymphocytes against the Plasmodium falciparum circumsporozoite protein. J. Immunol. 149, 966-971.

Stoute, J. A., Kester, K. E., Krzych, U., Wellde, B. T., Hall, T., White, K., et al. (1998). Long-term efficacy and immune responses following immunization with the RTS,S malaria vaccine. J. Infect. Dis. 178, 1139-1144. doi: 10.1086/515657

Tsuji, M., Mattei, D., Nussenzweig, R. S., Eichinger, D., and Zavala, F. (1994). Demonstration of heat-shock protein 70 in the sporozoite stage of malaria parasites. Parasitol. Res. 80, 16-21. doi: 10.1007/BF00932618

Valencia-Hernandez, A. M., Ng, W. Y., Ghazanfari, N., Ghilas, S., de Menezes, M. N., Holz, L. E., et al. (2020). A natural peptide antigen within the Plasmodium ribosomal protein RPL6 confers liver TRM cell-mediated immunity against malaria in mice. Cell Host Microbe 27, 950-962. doi: 10.1016/ j.chom.2020.04.010

van der Most, R. G., Murali-Krishna, K., Lanier, J. G., Wherry, E. J., Puglielli, M. T., Blattman, J. N., et al. (2003). Changing immunodominance patterns in antiviral CD8 T-cell responses after loss of epitope presentation or chronic antigenic stimulation. Virology 315, 93-102. doi: 10.1016/j.virol.2003.07.001

van Dijk, M. R., Waters, A. P., and Janse, C. J. (1995). Stable transfection of malaria parasite blood stages. Science 268, 1358-1362. doi: 10.1126/science.7761856
Vanderberg, J. P. (1975). Development of infectivity by the Plasmodium berghei sporozoite. J. Para-Sitol. 61, 43-50. doi: 10.2307/3279102

Weiss, W. R., and Jiang, C. G. (2012). Protective CD8+ T lymphocytes in primates immunized with malaria sporozoites. PLoS One 7:e31247. doi: 10.1371/journal. pone.0031247

Weiss, W. R., Sedegah, M., Beaudoin, R. L., Miller, L. H., and Good, M. F. (1988). CD8+ T cells (cytotoxic/suppressors) are required for protection in mice immunized with malaria sporozoites. Proc. Natl. Acad. Sci. U.S.A. 85, 573-576. doi: $10.1073 /$ pnas.85.2.573

World Health Organisation (2020). World Malaria Report 2020. Geneva: World Health Organisation.

Yoshida, N., Nussenzweig, R. S., Potocnjak, P., Nussenzweig, V., and Aikawa, M. (1980). Hybridoma produces protective antibodies directed against the sporozoite stage of malaria parasite. Science 207, 71-73. doi: 10.1126/science. 6985745

Zavala, F., Cochrane, A. H., Nardin, E. H., Nussenzweig, R. S., and Nussenzweig, V. (1983). Circumsporozoite proteins of malaria parasites contain a single immunodominant region with two or more identical epitopes. J. Exp. Med. 157, 1947-1957. doi: 10.1084/jem.157.6.1947

Zavala, F., Masuda, A., Graves, P. M., Nussenzweig, V., and Nussenzweig, R. S. (1985). Ubiquity of the repetitive epitope of the CS protein in different isolates of human malaria parasites. J. Immunol. 135, 2790-2793.

Conflict of Interest: The authors declare that the research was conducted in the absence of any commercial or financial relationships that could be construed as a potential conflict of interest.

Publisher's Note: All claims expressed in this article are solely those of the authors and do not necessarily represent those of their affiliated organizations, or those of the publisher, the editors and the reviewers. Any product that may be evaluated in this article, or claim that may be made by its manufacturer, is not guaranteed or endorsed by the publisher.

Copyright (c) 2021 Hon, Friesen, Ingmundson, Scheppan, Hafalla, Müller and Matuschewski. This is an open-access article distributed under the terms of the Creative Commons Attribution License (CC BY). The use, distribution or reproduction in other forums is permitted, provided the original author(s) and the copyright owner(s) are credited and that the original publication in this journal is cited, in accordance with accepted academic practice. No use, distribution or reproduction is permitted which does not comply with these terms. 